\title{
In-Vitro Investigation of CPH Drug-Montmorillonite Clay Interaction
}

\author{
Ebtesam Salem Omer Bamahmood, ${ }^{1}$ Adel A M Saeed, ${ }^{2 *}$ Abdul Rahman Alawi Bin Yahia ${ }^{1}$ \\ ${ }^{1}$ Department of Pharmaceutical Chemistry, University of Aden, Yemen \\ ${ }^{2}$ Departmaent of Chemistry, University of Aden, Yemen
}

\begin{abstract}
The aim of the present work is to explore a naturally occurring clay mineral Montmorillonite (MMT), purified from raw Yemeni bentonite clay, as adsorbent material for ciprofloxacin hydrochloride antibiotic (CPH) in order to investigate the interaction of CPH and MMT. CPH-MMT composites were synthesized and the study design involved the investigation of the effect of three variables, namely; the time, $\mathrm{pH}$ and concentration of drug, on the intercalation process. The drug loading and recovery mechanisms were examined and supported by diffusion kinetics laws and adsorption isotherm models. The statistical analysis of the effect of different factors on the adsorption process showed that there was a significant difference in the amount of $\mathrm{CPH}$ drug that adsorbed due to variations in these factors. This study showed that the equilibrium time attained after 4 hours and the $\mathrm{pH}$ of the drug solution played a crucial role in the intercalation process and the adsorption isotherm was fitted by the Langmuir model with maximum adsorption and followed the pseudo-second-order kinetics. Ciprofloxacin hydrochloride is proved to successfully intercalate into the interlayers of MMT. The intercalation of a drug in MMT follows pseudo-second order kinetics. It is recommended that the overall rate of the adsorption procedure is expected to be controlled by the chemical adsorption process. The adsorption process follows the Langmuir model with a maximum amount of $\mathrm{CPH}$ intercalated in MMT being $263.15 \mathrm{mg} / \mathrm{g}$. This indicates the homogeneous nature of the MMT surface and the formation of monolayer coverage of $\mathrm{CPH}$ on the surface of MMT.
\end{abstract}

Keywords: Adsorption, Natural sorbent, Montmorillonite, Antibiotic ciprofloxacin, Isotherm models, Kinetics

\section{Introduction}

Clay minerals have a beneficial effect on human life and civilization. Being an integral part of the earth, its history is older than the creation of man. Recently, much attention has been paid to clay minerals for several purposes and applications in pharmaceutical and nanomaterial industries, animal feed, removal of inorganic and organic pollutants. due to their abundance in nature, inexpensive material, and having unique structural properties. ${ }^{1-8}$ Ciprofloxacin hydrochloride salt (CPH; scientific name 1-cyclo propyl-6-floro-4-oxo-7(piperazin-1y1)-1,4-dihydroquinoline-3-carboxylicacidhydrochloride; with molecular formula $\mathrm{C}_{17} \mathrm{H}_{18} \mathrm{FN}_{3} \mathrm{OH}_{2} \mathrm{O}$.
$\mathrm{HCl}$, and molecular weight=385.8) (Figure 1) is an expanded spectrum antibiotic drug under fluoroquinolone class used to treat a number of gram - positive and gram-negative bacterial infections by interfering with the bacterial DNA gyrase and preventing bacterial cell development. ${ }^{9-12}$

$\mathrm{CPH}$ has an imperfect metabolization in human and animal bodies. This leads to unceasingly emergence in the aquatic environment and can reach nanograms per liter to micrograms per liter in both ground and surface water. ${ }^{1,13}$ Several methods can be applied to determine the specific surface, which is of great importance for various reactions such as adsorption, for example. Adsorption is a

\begin{tabular}{|l|l|}
\hline \hline Quick Response Code: & *Corresponding author: Adel A M Saeed, Department of Chemistry, Faculty of Science, Uni- \\
versity of Aden, Yemen \\
Received: 18 October, 2021 \\
Citation: Omer Bamahmood ES, Saeed AAM, Bin Yahia ARA. In-Vitro Investigation of CPH \\
Drug-Montmorillonite Clay Interaction. Curr Trends Toxi Pharma Res. 2021;1(1):1-12. D0I: \\
10.53902/CTTPR.2021.01.000501
\end{tabular}


surface phenomenon that one or more substances which are eventually present in a liquid phase would remove from that phase by accretion at the interface between a solid surface and the liquid. It is the transfer of organic/inorganic substances from a liquid phase onto the surface of a solid phase. Adsorption material should be categorized by a maximum surface area and a minimum volume. Adsorption mechanisms are normally classified as electrostatic, physical and chemical adsorption. The techniques can be applied in remediation, cleaning and wastewater treatments. ${ }^{14-17}$<smiles></smiles>

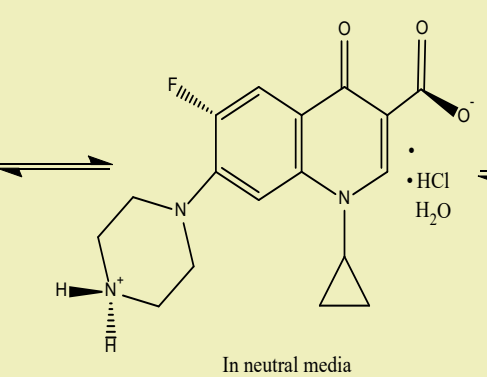

In neutral media

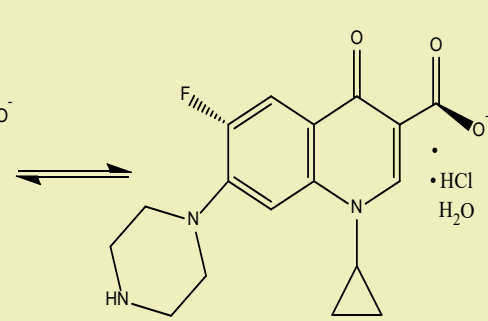

In basic media $(\mathrm{pH}=8.7)$
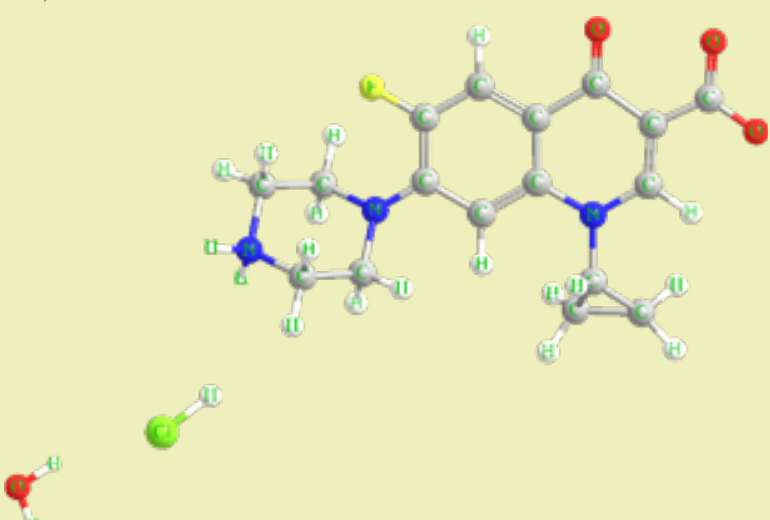

Figure 1: (A) Molecular structure and speciation of $\mathrm{CPH}$ under different media, (B) 3D structure of the neutral form.

Various adsorption isotherms and kinetic methods can be useful in designing experiments and solving pharmaceutical, nanomaterial, biophysical and bioanalytical problems. ${ }^{18-23}$ From environmental and medical points of view, this study is aimed to find out the optimum intercalation conditions to use Yemeni bentonite in removing $\mathrm{CPH}$ drug from wastewater and to investigate the preparation of controlled drug delivery system of CPH using MMT clay mineral. We examined and discussed the probable sorption process, based on the experimental data by applying several adsorption isotherms and kinetic models.

\section{Experimental process}

\section{Clay mineral}

The sample of bentonite clay was obtained kindly from Geological Survey and Mineral Resources in Hadramout as a rock form. This raw rock $(\sim 600 \mathrm{~g})$ was dried $\left(80 \pm 1^{\circ} \mathrm{C}\right)$ in an air oven, crushed to reduce the size of particles. The crushing of clay was carried out using standard method ${ }^{24,25}$ which then followed by passing through the standard sieve of $1000 \mu \mathrm{m}$ and then the clay milled by miller to more reduction of particle size which confirmed by passing through the standard sieve of $75 \mu \mathrm{m}$ (done in the Geological Survey and Mineral Resources in Aden).

\section{Chemicals}

CPH (purity=99\%) was purchased from RFA Pharma company, Yemen. Deionized water (Zero electrolyte, Aden Pharma, Yemen), $\mathrm{HCl}$ (37\%, Merck. USA), $\mathrm{NaOH}$ (99\%, Labtech International Ltd., Korea), $\mathrm{KH}_{2} \mathrm{PO}_{4}$ (99\%, Labtech International Ltd., Korea), $\mathrm{H}_{2} \mathrm{SO}_{4}(98 \%$, Merck, USA), Ethanol (96\%, Merck, USA), NaCl (98\%, Himedia Laboratories Pvt Ltd., India), KBr (98\%, Sigma-Alderich, Germany) were used without further treatment.

\section{Adsorbent preparation}

To obtain bentonite in Na-form,100g of lumps raw bentonite were dispersed in $1 \mathrm{~L}$ of $0.1 \mathrm{M} \mathrm{NaCl}$ solution, stirred for $12 \mathrm{~h}$ and centrifuged at $5000 \mathrm{rpm}$ and the procedure was repeated three times. Finally, the slurry was centrifuged at 5000rpm and washed with deionized water to remove chloride ion (as tested by $\mathrm{AgNO}_{3}$ solution). According to the Stoke's law of sedimentation, the purified MMT was obtained by dispersing the $75 \mathrm{~g}$ Na-bentonite wet cake in $5 \mathrm{~L}$ deionized water and collecting the supernatant dispersion of particles $(<2 \mu \mathrm{m})$ after the pre-calculated time $(10 \mathrm{~h})$ at $30^{\circ} \mathrm{C}$. The MMT slurry was dried at $90-100^{\circ} \mathrm{C}$ and ground to pass through sieve mesh NO. 200.24,25 


\section{Intercalation conditions}

To investigate the interaction of CPH and MMT, CPH-MMT composites were characterized as follow.

\section{Selection of solvent \& wavelength}

Using a S-3100 (Scinco, Korea) spectrophotometer the UV-Vis spectra of $\mathrm{CPH}\left(7 \mathrm{mg} / \mathrm{L}\right.$ ) in different solvents used (i.e., $\mathrm{H}_{2} \mathrm{O}, 1 \mathrm{M} \mathrm{HCl}$, $10 \%$ methanol, and $1 \mathrm{M} \mathrm{NaOH}$ ) were recorded between 200-400nm. The CPH showed maximum absorption $\left(\Lambda_{\text {max }}\right)$ was at $273 \mathrm{~nm}$ in water (Figure 2). This solvent was chosen for the next studies because of its excellent absorption, furthermore, its economic and low environmental impacts. Choosing water as a solvent agreed with the previous results obtained for the $\mathrm{CPH}$ determination in ophthalmic solutions. ${ }^{26}$

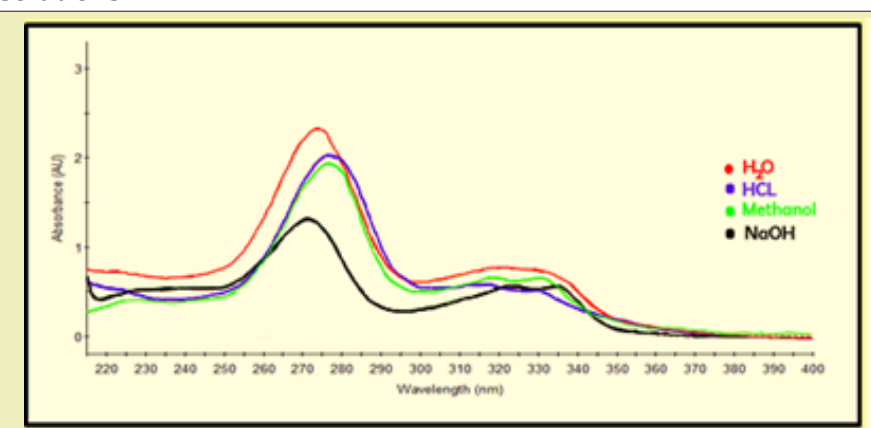

Figure 2: Solvent selection for maximum absorption.

\section{Preparation of calibration curve}

Five standard solutions of $\mathrm{CPH}$ in $\mathrm{H}_{2} \mathrm{O}$ were prepared within the concentration range of $4 \mathrm{mg} / \mathrm{L}$ to $14 \mathrm{mg} / \mathrm{L}$ (Table 1 ). It was found that the aqueous solution of CPH obeys Lambert-Beer law (Table 2, Figure 3).

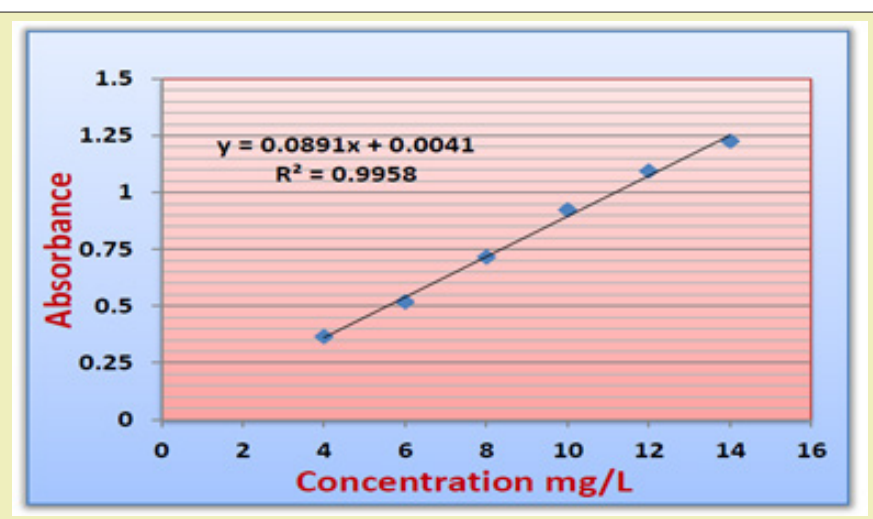

Figure 3: Calibration curve of $\mathrm{CPH}$ solutions at $273 \mathrm{~nm}$.

\section{Effect of pH}

To recognize the influence of $\mathrm{pH}$ on drug adsorption, the experiments were conducted at different $\mathrm{pH}$ values ranging from 3 to 11 . While doing so, the other parameters, e.g., time and initial drug concentration were unchanged. Effect of $\mathrm{pH}$ of the reaction medium on adsorption of CPH was studied by treating $100 \mathrm{mg}$ of
MMT with $10 \mathrm{ml}$ of $3000 \mathrm{mg} / \mathrm{L}$ aqueous drug solution at different $\mathrm{pH}$ values $(3,4,5,6,7.5,9,10$ and 11$)$, adjusted by $1 \mathrm{M} \mathrm{NaOH}$ or $1 \mathrm{M}$ $\mathrm{HCl}$. The solutions were shaken for $4 \mathrm{~h}$ at room temperature. Finally, the reaction mixtures were filtered through 0.45 membrane filter and concentration of drug in filtrates was determined at $273 \mathrm{~nm}$. All the experiments were measured in triplicate and an average value were used in the analysis. ${ }^{27}$

Table1: Standard Calibration of an aqueous solution of $\mathrm{CPH}$.

\begin{tabular}{|l|l|l|}
\hline \multicolumn{1}{|c|}{ No. } & Concentration $\mathbf{~ m g / L}$ & \multicolumn{1}{c|}{ Absorbance } \\
\hline 1 & 4 & $0.3642 \pm 0.00065$ \\
\hline 2 & 6 & $0.5173 \pm 0.00041$ \\
\hline 3 & 8 & $0.7142 \pm 0.00072$ \\
\hline 4 & 10 & $0.9222 \pm 0.00070$ \\
\hline 5 & 12 & $1.0928 \pm 0.00060$ \\
\hline 6 & 14 & $1.2244 \pm 0.00121$ \\
\hline
\end{tabular}

Table 2: Calibration curve parameters of an aqueous solution of $\mathrm{CPH}$.

\begin{tabular}{|l|l|}
\hline \multicolumn{1}{|c|}{ Parameter } & \multicolumn{1}{c|}{ Value (unit) } \\
\hline$\Lambda_{\max }$ & $273(\mathrm{~nm})$ \\
\hline Linearity R ${ }^{2}$ & 0.9958 \\
\hline Beer's Law Limit & $4-14(\mathrm{mg} / \mathrm{L})$ \\
\hline Regression Equation & $\mathrm{Y}=0.0891+0.0041$ \\
\hline Slope & 0.0891 \\
\hline Intercept & 0.0041 \\
\hline Limit Of Detection (LOD) & $0.8933(\mathrm{mg} / \mathrm{L})$ \\
\hline Limit Of Quantification (LOQ) & $2.707(\mathrm{mg} / \mathrm{L})$ \\
\hline Molar Absorptivity & $3.427942 \mathrm{X} 10^{4}(\mathrm{~L} / \mathrm{mole.cm})$ \\
\hline Sandell's Sensitivity & $0.0107\left(\mu \mathrm{g} / \mathrm{cm}^{2} / 0.001 \mathrm{a} . \mathrm{u}.\right)$ \\
\hline
\end{tabular}

\section{Effect of initial drug concentration}

The initial concentration of the drug required for maximum adsorption was determined using its different initial concentrations. The other parameters were kept constant. To find out the maximum initial concentration of CPH, 100mg of MMT was mixed with $10 \mathrm{ml}$ of drug solution having a different concentration ranging from $1800 \mathrm{mg} / \mathrm{L}$ to $3200 \mathrm{mg} / \mathrm{L}$. The $\mathrm{pH}$ of drug solutions was adjusted to 7.5 using $\mathrm{NaOH}$ for all cases. Finally, the reaction mixtures were filtered and concentration of drug in filtrates was determined at optimum wavelength. All the experiments were performed in triplicate and an average value was used in the analysis. ${ }^{28} \mathrm{Ad}-$ sorption capacity on clay was calculated by the difference of initial concentration and equilibrium concentration of drug in solution as given below

$$
q e=\frac{\left(C_{o}-C_{e}\right) V}{m}
$$

where qe (adsorption capacity) is the amount of drug adsorbed at equilibrium $(\mathrm{mg} / \mathrm{g}) ; \mathrm{C}_{\mathrm{o}}$, the initial drug concentration in solution 
$(\mathrm{mg} / \mathrm{L}) ; \mathrm{C}_{\mathrm{e}}$, the drug concentration in solution at equilibrium $(\mathrm{mg} / \mathrm{L}) ; \mathrm{m}$, the mass of clay used ( $\mathrm{g}$ ) and $\mathrm{V}$, the volume of drug solution in $\mathrm{L}$.

The percentage of the drug adsorbed (\% removal), is calculated from the equation below: ${ }^{29}$

$$
\% \text { sorption }=\frac{C_{o}-C_{e}}{C_{0}} \times 100
$$

\section{Effect of time}

The time required for maximum intercalation of $\mathrm{CPH}$ into the interlayers of MMT was investigated. The experiments were established at several time periods, while the other parameters, e.g, initial drug concentration (3000mg/L) and $\mathrm{pH}$ (7.5) were fixed. To determine the time for maximum adsorption of $\mathrm{CPH}$ on MMT, $100 \mathrm{mg}$ of MMT was dispersed in $10 \mathrm{ml}$ of $3000 \mathrm{mg} / \mathrm{L}$ of CPH solution and shaken for $0.50,1,2,3,4,6,8$, and $12 \mathrm{~h}$ at $25^{\circ} \mathrm{C}$. Finally, the reaction mixtures were filtered through 0.45 membrane filter and concentration of drug in the filtrate was determined by UVVis spectrophotometer at $\lambda_{\max }=273 \mathrm{~nm}$. Triplicate measurements provided an average value.

\section{Kinetics and adsorption equilibrium of $\mathrm{CPH}$}

To analyze the adsorption kinetics of $\mathrm{CPH}$ on MMT, correlations time-adsorbed amounts were investigated, through the testing of several mathematical expressions corresponding to various models namely: pseudo-first-order, pseudo-second-order, secondorder and intraparticle diffusion models have been applied to determine the adsorption mechanism. ${ }^{30}$ Equilibrium studies were conducted using the batch equilibrium technique. Adsorption equilibrium isotherms are a good way to explain the adsorption system. It provides information about the adsorbate and adsorbent surface properties. Several isotherms were used (i.e. Langmuir, Freundlich, Temkin, and Dubinin-Radushkevich (D-R)) to describe the adsorption data. ${ }^{31}$

\section{Statistical analysis}

The determination of the best isotherm and kinetic models is only possible through the analysis of the correlation coefficient $\left(\mathrm{R}^{2}\right)$. Although efficient, this indicator is limited to solve isotherm models that present linear forms. ${ }^{32}$

Therefore, in this work, different error functions (i.e., $\chi^{2}$, ARE\%, SAE, RMSE, SSE) were used to assess the models in order to discover the isotherm model most suitable and validation of kinetic models for representing the experimental data. ${ }^{33}$

\section{Results and Discussion}

\section{MMT amount}

The amount of clay mineral MMT that recovered by sedimentation method of purification is small $(2.70 \mathrm{~g} \pm 0.45)$ compared with initial weight of bentonite clay (100g for each time of purification). Although this method is time-consuming and yields are low, a highly purified clay mineral can be obtained without damage to initial structure. ${ }^{34}$

\section{Optimization of the intercalation conditions of $\mathrm{CPH}$ on MMT}

\section{Effect of $\mathrm{pH}$}

Figure 1 illustrates the effect of $\mathrm{pH}$ change on the structure of $\mathrm{CPH}$ in which the $\mathrm{pH}$ of the drug solution has permanently played a vital role in the intercalation process. $\mathrm{pKa}_{1}$ and $\mathrm{pKa}_{2}$ values of $\mathrm{CPH}$ are 6.1 and 8.7 where the cationic form of $\mathrm{CPH}$ due to protonation of the amine group in the piperazine residue is utmost common when solution $\mathrm{pH}$ is below 6.1. Above $\mathrm{pH}$ 8.7, the anionic form of $\mathrm{CPH}$ (due to the loss of a proton from the carboxylic group) prevails. Between pH 6.1 and 8.7, the zwitterionic form of CPH becomes the dominant species resulting from the charge balance of the two groups mentioned above. ${ }^{28}$

Significant difference was found on the amount of $\mathrm{CPH}$ that adsorbed due to the different $\mathrm{pH}$ values $(\mathrm{p}<0.05)$ and $\mathrm{pH} 7.5$ was found as optimum $\mathrm{pH}$ for the adsorption process. In acidic to neutral conditions with initial CPH concentration of $3000 \mathrm{mg} / \mathrm{L}$, the adsorption of CPH on MMT was found to gradually increase between $\mathrm{pH} 3$ and $\mathrm{pH} 7.5$ from $242.53 \pm 0.71 \mathrm{mg} / \mathrm{g}$ to $293.70 \pm 0.02 \mathrm{mg} / \mathrm{g}$, as denoted in Figure 4. This can be explained as $\mathrm{CPH}$ is positive below $\mathrm{pH}=6.1\left(\mathrm{pKa}_{1}=6.1\right)$ and predominantly zwitterionic between 6.1 and $<8.7$ allowing adsorption onto the negatively charged clay mineral surfaces. Although the ratio of zwitterion/cation form increases gradually with $\mathrm{pH}$, the positive charge of the amine group of zwitterion may still contribute to the adsorption interaction. ${ }^{27}$ Wu et al.s' study of adsorption of CPH on MMT found that starting with an initial CPH concentration of $1500 \mathrm{mg} / \mathrm{L}$, the amount of $\mathrm{CPH}$ adsorption was relatively constant at $\sim 295 \mathrm{mg} / \mathrm{g}$ in the $\mathrm{pH} 3-8$ range. ${ }^{28}$

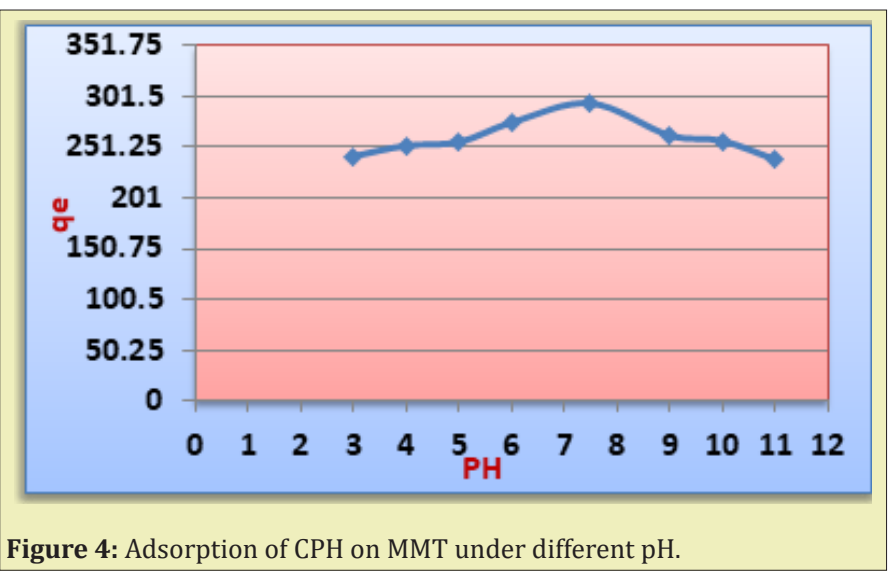

Also, the CPH adsorption study by Chih-Jen Wang et al showed that the amount adsorbed maintained at $290-300 \mathrm{mg} / \mathrm{g}$ in the $\mathrm{pH}$ 
range of 2.8-8.8. ${ }^{27}$ Greatest adsorption onto MMT was observed at $\mathrm{pH} 7.5$ when the predominant $\mathrm{CPH}$ species was in the zwitterionic form. These data suggest that the zwitterionic form of $\mathrm{CPH}$ enhances its adsorption onto clay mineral surfaces. This result is approved by Hamilton et al which confirmed that the changes in dispersion $\mathrm{pH}$ produced profound differences in the amount of CPH adsorbed onto MMT and kaolinite where CPH adsorption onto MMT was observed to increase between $\mathrm{pH} 1$ and $7.5 .{ }^{35}$

Above $\mathrm{pH} 8.7\left(\mathrm{pKa}_{2}=8.7\right)$ reduced $\mathrm{CPH}$ adsorption occurred presumably due to $\mathrm{CPH}$ being in its mononegative state causing it to be repelled from the clay mineral surface. As the $\mathrm{pH}$ increased, the amount of $\mathrm{CPH}$ adsorbed decreased sharply at $\mathrm{pH} 11$ to $239.70 \pm 0.44 \mathrm{mg} / \mathrm{g}$ (see Figure 4). The sharp decrease in $\mathrm{CPH}$ adsorption when solution $\mathrm{pH}$ was approaching or above its $\mathrm{pKa}_{2}$ confirmed that cation exchange was no longer dominating. ${ }^{27}$

The adsorption of CPH on MMT indicated that hydrogen bonding between the keto carbonyl group and coordinated water in the interlayer of MMT was mainly responsible for the $\mathrm{CPH}$ adsorption in alkaline aqueous solution. This comes to an agreement with Qingfeng Wu et al study of adsorption of CPH on MMT, wherein with the $\mathrm{pH}$ increase, the amount of $\mathrm{CPH}$ adsorbed decreased sharply to $210 \mathrm{mg} / \mathrm{g}$ at $\mathrm{pH} 11$. The sharp decrease in $\mathrm{CPH}$ adsorption when solution $\mathrm{pH}$ was approaching or above its $\mathrm{pKa}_{2}{ }^{28}$ This is also approved by Chih-Jen Wang et al work where the abrupt diminution in the amount of $\mathrm{CPH}$ adsorbed was $247 \mathrm{mg} / \mathrm{g}$ as $\mathrm{pH}$ reached $11 .^{27}$

Such behaviors in a significant diminution of $\mathrm{CPH}$ adsorption to the soil, goethite, and kaolinite were reported. However, the onset pH corresponding to a decrease in $\mathrm{CPH}$ adsorption was close to the pKa1 of CPH in those cases compared to close to $\mathrm{pKa}_{2}$ in this study. The variation of $\mathrm{CPH}$ adsorption under different $\mathrm{pH}$ conditions in these studies could be attributed to the effect of the substrate minerals. The charge in MMT is less $\mathrm{pH}$-dependent due to the permanent layer charges. Further, goethite and kaolinite have pH-dependent surface charge and their CEC varies with solution $\mathrm{pH}$. Thus, the type of surface charge plays a significant role in $\mathrm{CPH}$ uptake under different $\mathrm{pH}$ conditions. ${ }^{28}$

\section{Effect of initial CPH concentration}

Initial concentration is one of the effective factors on adsorption efficiency. ${ }^{36}$ The amount of $\mathrm{CPH}$ adsorbed due to the different initial concentrations of a drug differed significantly at $\mathrm{p}<0.05$ and a concentration of $3000 \mathrm{mg} / \mathrm{L}$ was found as the optimum concentration for the adsorption process. At $\mathrm{pH} 7.5$, the intercalation of $\mathrm{CPH}$ within MMT layers is affected by its initial amount present in the solution.

As the $\mathrm{CPH}$ amount in the solution increases from 18 to 30mg/ $\mathrm{mL}(1800-3000 \mathrm{mg} / \mathrm{L})$, the amount of CPH intercalated within MMT layers increased from $176.15 \pm 0.01 \mathrm{mg} / \mathrm{g}$ to $252.75 \pm 0.27 \mathrm{mg} / \mathrm{g}$ (Figure 5), this may be due to the higher adsorption rate and the utilization of all available active sites of MMT for the adsorption in higher $\mathrm{CPH}$ concentration in which the adsorption sites take up the available adsorbate more quickly at higher concentrations as a result of increased collision possibilities. ${ }^{37}$ It is also noted that there was a decrease in intercalation (\%) from $97.86 \pm 0.01 \%$ to $84.24 \pm 0.01 \%$ (Figure 5) which can be attributed to the saturation of available active sites on MMT above a certain concentration of $\mathrm{CPH}$ where the number of available adsorption sites becomes lower at higher concentrations (i.e., $3200 \mathrm{mg} / \mathrm{L}$ ). ${ }^{38}$ Therefore, it could be concluded that due to the higher availability of the adsorption sites, nearly $98 \%$ adsorption was obtained at a lower concentration of the initial drug.

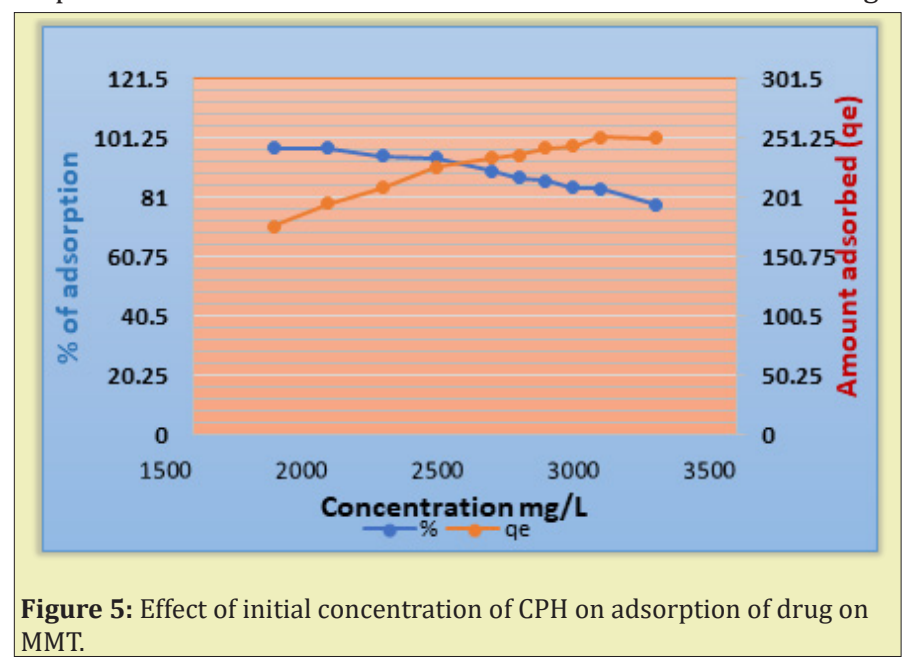

\section{Time effect}

Contact time is one of the important parameters for the assessment of the practical application of the adsorption process. ${ }^{39}$ The effect of contact time between CPH and MMT on the intercalation process have been studied at different times. The results of the study of time required for maximum intercalation are summarized in Table 3. Difference of the adsorbed amount of $\mathrm{CPH}$ at changed time points is significant $(\mathrm{p}<0.05)$. The intercalation of CPH in MMT is due to the occurrence of ion-exchange reaction between the interlayer $\mathrm{Na}^{+}$ions and cationic $\mathrm{CPH}$ molecules. At $\mathrm{pH} 4.5,87.22 \pm 0.03 \%$ of $3000 \mathrm{mg} / \mathrm{L}$ of $\mathrm{CPH}$ was intercalated within $4 \mathrm{~h}$ interaction time, which remained constant almost up to $12 \mathrm{~h}$. Regarding the drug-clay interaction time, the percentage of the loaded drug increases rapidly through the first hour with increasing the loading time, about $86.42 \pm 0.07 \%$ of $\mathrm{CPH}$ initially in solution was incorporated in the first hour. The adsorption seemed to continue speedily when the numbers of obtainable sites are considerably larger than the number of species to be adsorbed, ${ }^{36}$ followed by a gradual increase of up to $4 \mathrm{~h}(87.22 \pm 0.03 \%)$. No relevant variations in the $\mathrm{CPH}$ amount incorporated into MMT clay-in particular-from 4 to $12 \mathrm{~h}$ were observed which remained almost constant up to $12 \mathrm{~h}$ (Figure 6) as no 
more occupation of active sites on the adsorbent and therefore no additional adsorption is probable, ${ }^{40}$ also after a certain time period, the vacant sites get occupied by molecules of adsorbate which lead to creating a repulsive force between the adsorbate on the adsorbent surface and in majority phase. ${ }^{41}$ Thus, interaction time was set to $4 \mathrm{~h}$ in the subsequent experiments of $\mathrm{CPH}$ adsorption isotherms and $\mathrm{pH}$ studies in order to guarantee the right balance between the contact time and the appropriate $\mathrm{CPH}$ incorporation.

Table 3: Data analysis of Time effect on the adsorption process.

\begin{tabular}{|l|l|l|l|}
\hline Time $(\mathbf{h})$ & \multicolumn{1}{|c|}{$\mathbf{C}_{\mathbf{e}}(\mathbf{m g} / \mathbf{L})$} & $\mathbf{Q}_{\mathbf{t}}(\mathbf{m g} / \mathbf{g})$ & \multicolumn{1}{c}{ of adsorption } \\
\hline 0.5 & $454.13 \pm 0.22$ & $254.58 \pm 0.02$ & $84.86 \pm 0.01$ \\
\hline 1 & $407.25 \pm 1.26$ & $259.27 \pm 0.23$ & $86.42 \pm 0.07$ \\
\hline 2 & $397.86 \pm 0.23$ & $260.21 \pm 0.02$ & $86.73 \pm 0.01$ \\
\hline 3 & $394 \pm 1.029$ & $260.60 \pm 0.02$ & $86.86 \pm 0.04$ \\
\hline 4 & $383.12 \pm 0.72$ & $261.68 \pm 0.03$ & $87.22 \pm 0.03$ \\
\hline 6 & $384.01 \pm 1.39$ & $261.59 \pm 0.24$ & $87.19 \pm 0.04$ \\
\hline 8 & $384.01 \pm 0.31$ & $261.59 \pm 0.03$ & $87.19 \pm 0.01$ \\
\hline 12 & $384.64 \pm 0.88$ & $261.53 \pm 0.01$ & $87.17 \pm 0.03$ \\
\hline
\end{tabular}

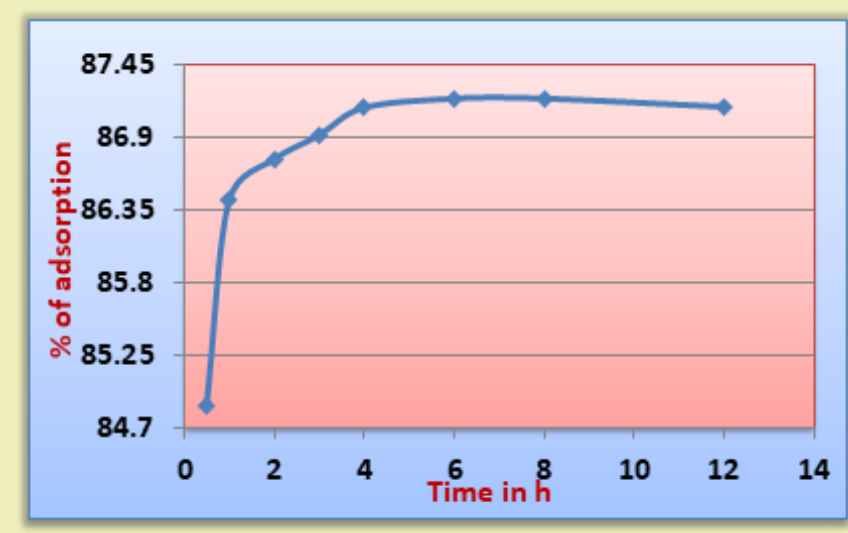

Figure 6: Effect of contact time on adsorption of $\mathrm{CPH}$ on MMT.

\section{Kinetics of CPH adsorption}

\section{Pseudo-first-order model}

The pseudo-first-order equation can be expressed as below:

$$
\ln \left(q_{e}-q_{t}\right)=\operatorname{In} q_{e}-k_{1} t
$$

where $k_{1}$ is the pseudo-first-order rate constant $\left(h^{-1}\right), q_{t}$ is the amount of drug adsorbed (mg/g) at different times $t$, and $q_{e}$ is the amount of drug adsorbed at equilibrium (mg/g). A plot of $\ln \left(\mathrm{q}_{\mathrm{e}}-\mathrm{q}_{\mathrm{t}}\right)$ versus $t$ for the adsorption of $\mathrm{CPH}$ on MMT surface was employed to generate the intercept value of $\ln \mathrm{q}_{\mathrm{e}}$ and the slope of $\mathrm{k}_{1}$ as indicated in Figure $7 .^{30}$

\section{Pseudo-second-order model}

The pseudo-second-order kinetic equation can be represented as below:

$$
\frac{t}{q_{t}}=\frac{1}{k_{2} q_{e}^{2}}+\frac{1}{q_{e}} t
$$

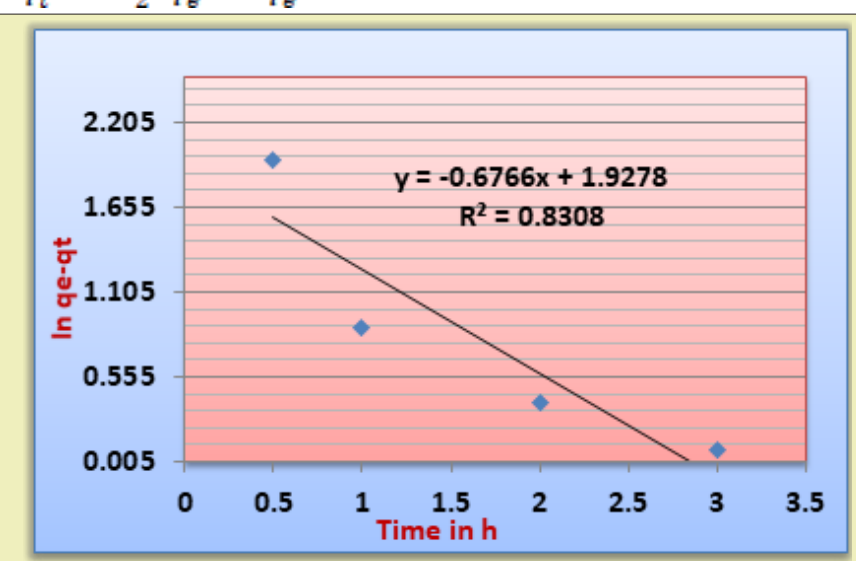

Figure 7: Pseudo-first-order model of $\mathrm{CPH}$ adsorption on MMT.

where $\mathrm{k}_{2}$ is the pseudo-second-order rate constant, $\mathrm{q}_{\mathrm{t}}$ is the amount of drug adsorbed (mg/g) at different times $t$, and $q_{e}$ is the amount of drug adsorbed at equilibrium (mg/g). The plot of $t / q_{t}$ versus $\mathrm{t}$ for $\mathrm{CPH}$ adsorption onto MMT was employed to generate the intercept and slope values as indicated in Figure 8. From the slope and intercept values, $\mathrm{q}_{\mathrm{e}}$ and $\mathrm{k}_{2}$ values were calculated as $\mathrm{k}_{2}=$ (slope $)^{2} /$ intercept and $\mathrm{q}_{\mathrm{o}}=1 /$ slope.

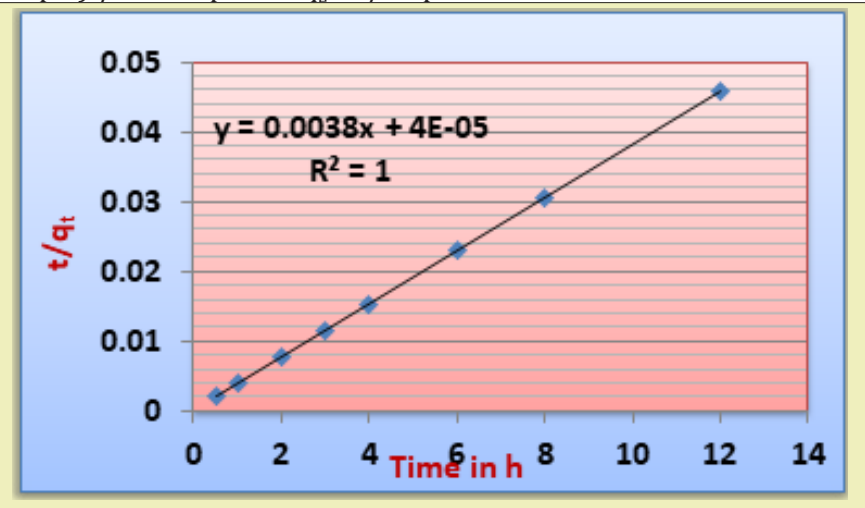

Figure 8: Pseudo-second-order model of CPH adsorption on MMT.

\section{Second-order model}

The second-order kinetic equation is represented as below:

$$
\frac{1}{C_{e}}=K_{2} t+\frac{1}{C_{0}}
$$

where $\mathrm{C}_{\mathrm{o}}$ and $\mathrm{C}_{\mathrm{e}}(\mathrm{mg} / \mathrm{L})$ is the concentration of solute at equilibrium and at time $t$, respectively, and $K_{2}$ (L/mg.h) is the second-order rate constant. The plot of $1 / C_{e}$ versus $t$ will give a linear relationship with $K_{2}$ and $1 / C_{o}$ as slope and intercept, respectively (Figure 9). ${ }^{42}$

The conventionality between the model predicted values and experimental results was represented by the correlation 
coefficients. more finding is based on the agreement between theoretical and experimental data. ${ }^{43}$ Table 4 summarize the experimental kinetic results with their predictable parameters. The results indicate that the pseudo-second-order kinetics $\left(\mathrm{R}^{2}=1\right)$ is more suitable than the pseudo-first-order kinetic $\left(\mathrm{R}^{2}=0.8308\right)$ and second-order kinetics $\left(\mathrm{R}^{2}=0.4096\right)$ for adsorption of $\mathrm{CPH}$ on MMT which approve that the adsorption follows the pseudosecond-order reaction. As shown in Table 4, the calculated $\mathrm{q}_{\mathrm{e}}$ value obtained from the first-order kinetic model $(6.87 \mathrm{mg} / \mathrm{g})$ does not give responsible value, which is too low compared with experimental $\mathrm{q}_{\mathrm{e}}$ value $(261.68 \mathrm{mg} / \mathrm{g})$. The evaluated $\mathrm{q}_{\mathrm{e}}$ value of the pseudo-second-order model $(263.15 \mathrm{mg} / \mathrm{g})$ perfectly predicts the adsorption kinetics over the entire working time. Consequently, this model has sufficient precise and suitable predictions of the kinetics and adoption of CPH- MMT interaction. ${ }^{44}$ It is mentioned that the overall rate of the adsorption procedure is expected to be controlled by the chemisorption process involving valence forces through the sharing or exchange of electrons between sorbent and sorbate. ${ }^{45}$ The rate of reaction is directly proportional to the number of active sites on the surface of the adsorbent. ${ }^{44}$

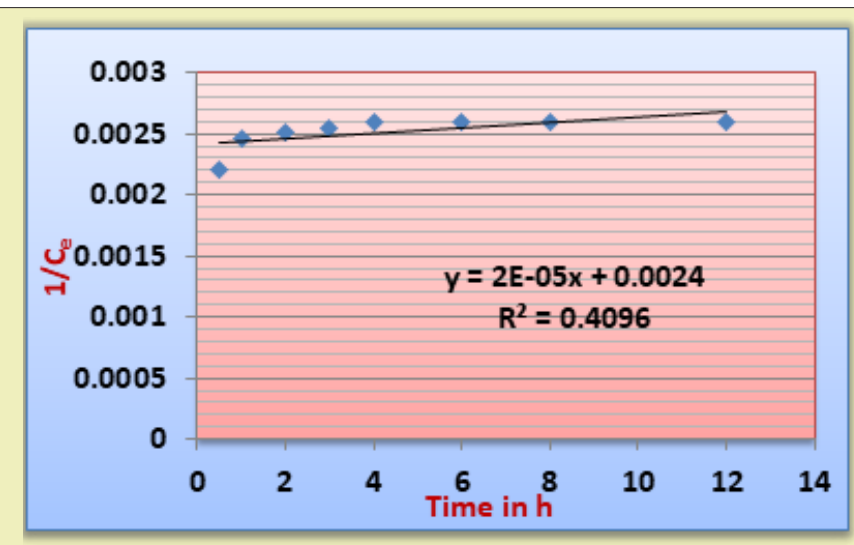

Figure 9: Second-order model of CPH adsorption on MMT.

\section{Validity of kinetic models}

The applicability of both pseudo-first order and pseudo-second order models for the adsorption of CPH on MMT was verified using different error functions, namely, the Chi-square test, $\chi^{2}$, the residual root mean square errors, RMSE, and the sum of squares of the errors (SSE). The standard equations are:

$$
\begin{aligned}
& \chi 2=\sum_{i=1}^{N} \frac{\left(q e_{e x p}-q e_{c a l}\right)^{2}}{q e_{c a l}} \\
& R M S E=\sqrt{\frac{1}{N-2} \sum_{i=1}^{N} \frac{\left(q e_{e x p}-q e_{c a l}\right)^{2}}{q e_{c a l}}} \\
& S S E=\left(q e_{\exp }-q e_{c a l}\right)^{2}
\end{aligned}
$$

where $\mathrm{qe}_{\text {exp }}$ and $\mathrm{qe}_{\text {cal }}$ represent the experimental and calculated values of adsorption capacity $(\mathrm{mg} / \mathrm{g})$, and $\mathrm{N}$ is the number of experimental data points used in the linear plot of each model. ${ }^{46}$ The validity of these models was compared by judging the low values of $\chi^{2}$, SSE and RMSE which indicates the goodness of fit. ${ }^{47}$ The values of ( $\chi^{2}$, SSE, and RMSE) obtained for the two models are listed in Table 5. We see that the pseudo-second-order kinetic model yields the lowest values of $\chi^{2}$, SSE $\%$ and RMSE $(0.01,2.14$ and 0.04 , respectively). Whereas, the pseudo-first-order model shows very high values of $\chi^{2}$, SSE and RMSE (9451.56, 64932.21 and 39.69) in that order. This agrees with the previous values of both $\mathrm{R}^{2}$ and $\mathrm{qe}_{\text {cal }}$ obtained earlier for the pseudo-second-order to further prove the suitability of the pseudo-second-order kinetic to describe the adsorption process of CPH on MMT.

Table 4: Kinetic parameters for the adsorption of CPH on MMT, with an initial concentration of $3000 \mathrm{mg} / \mathrm{L}$.

\begin{tabular}{|l|l|l|}
\hline \multicolumn{1}{|c|}{ Model } & \multicolumn{1}{c|}{ Parameter } & \multicolumn{1}{c|}{ Value } \\
\hline Experimental data & $\mathrm{q}_{\mathrm{e}}(\mathrm{mg} / \mathrm{g})$ & 261.68 \\
\hline \multirow{4}{*}{ Pseudo-first order } & $\mathrm{R}^{2}$ & 0.8308 \\
\cline { 2 - 3 } & $\mathrm{q}_{\mathrm{e}}(\mathrm{mg} / \mathrm{g})$ & 6.87 \\
\cline { 2 - 3 } & $\mathrm{k}_{1}\left(\mathrm{~h}^{-1}\right)$ & $1.77 \times 10^{-1}$ \\
\hline \multirow{4}{*}{ Pseudo-second order } & $\mathrm{R}^{2}$ & 1 \\
\cline { 2 - 3 } & $\mathrm{q}_{\mathrm{e}}(\mathrm{mg} / \mathrm{g})$ & 263.15 \\
\cline { 2 - 3 } & $\mathrm{k}_{2}(\mathrm{~g} / \mathrm{mg} \mathrm{h})$ & $3.60 \times 10^{-1}$ \\
\hline \multirow{4}{*}{ Second-order } & $\mathrm{R}^{2}$ & 0.4096 \\
\cline { 2 - 3 } & $\mathrm{K}_{2}(\mathrm{~L} / \mathrm{mg} . \mathrm{h})$ & $2 \times 10^{-5}$ \\
\cline { 2 - 3 } & $\mathrm{C}_{0(\mathrm{cal})}(\mathrm{mg} / \mathrm{L})$ & 416.66 \\
\cline { 2 - 3 } & $\mathrm{C}_{0(\mathrm{exp})}(\mathrm{mg} / \mathrm{L})$ & 383.12 \\
\hline
\end{tabular}

Table 5: Validity of kinetic parameters.

\begin{tabular}{|l|l|l|}
\hline \multicolumn{1}{|c|}{ Models } & \multicolumn{1}{c|}{ Parameter } & \multicolumn{1}{c|}{ Value } \\
\hline \multirow{3}{*}{ Pseudo-first order } & $\chi^{2}$ & 9451.56 \\
\cline { 2 - 3 } & SSE & 64932.21 \\
\cline { 2 - 3 } & RMSE & 39.69 \\
\hline \multirow{2}{*}{$\begin{array}{l}\text { Pseudo-second } \\
\text { order }\end{array}$} & $\chi^{2}$ & 0.01 \\
\cline { 2 - 3 } & SSE & 2.14 \\
\cline { 2 - 3 } & RMSE & 0.04 \\
\hline
\end{tabular}

\section{Kinetics mechanism}

The pseudo-first-order kinetic, pseudo-second-order kinetic and second-order kinetic models could not identify the diffusion mechanism and the rate-limiting step in adsorption process but sorption kinetics may alternatively be described from mechanistic point view. ${ }^{48}$ In order to understand the rate-controlling step, the experimental data were subjected to the intraparticle diffusion model. The rate constant of intraparticle diffusion is calculated by linearization of equation (9): 


$$
q_{t}=k_{i p} \times t^{1 / 2}+C_{i}
$$

where $\mathrm{q}_{\mathrm{t}}$ is the amount of drug adsorbed $(\mathrm{mg} / \mathrm{g}$ ) at different times $t, C_{i}$ is the intercept and $k_{i p}$ is the intraparticle diffusion rate constant $\left(\mathrm{mg} / \mathrm{g} \mathrm{h}^{1 / 2}\right){ }^{44}$ The data for analysis of the said model are summarized in Table 6 . According to this model, the plot of uptake, $\mathrm{q}_{\mathrm{t}^{\prime}}$ versus the square root of time $\left(\mathrm{t}^{1 / 2}\right)$ should be linear. Intraparticle diffusion is the rate-controlling step if the lines pass through the origin. When the plots do not pass through the origin, this is indicative of some degree of boundary layer control and this displays that the intraparticle diffusion is not the only ratelimiting step, but also additional kinetic models may control the rate of adsorption, all of which may be operating consecutively. The intraparticle diffusion rate constant, $\mathrm{k}^{\mathrm{i}}$, value can be obtained from the slope of the straight-line portions of the plot of $\mathrm{q}_{\mathrm{t}}$ versus $\mathrm{t}^{1 / 2}{ }^{45}$

Table 6: Data for analysis intraparticle diffusion model.

\begin{tabular}{|l|l|l|}
\hline \multicolumn{1}{|c|}{ Time (h) } & \multicolumn{1}{c|}{$\mathbf{t}^{1 / 2}$} & \multicolumn{1}{c|}{$\mathbf{q}_{\mathbf{t}}$} \\
\hline 0.5 & 0.7 & $254.58 \pm 0.02$ \\
\hline 1 & 1 & $259.27 \pm 0.23$ \\
\hline 2 & 1.41 & $260.21 \pm 0.02$ \\
\hline 3 & 1.73 & $260.60 \pm 0.02$ \\
\hline 4 & 2 & $261.68 \pm 0.03$ \\
\hline 6 & 2.45 & $261.59 \pm 0.24$ \\
\hline 8 & 2.83 & $261.59 \pm 0.03$ \\
\hline 12 & 3.46 & $261.53 \pm 0.01$ \\
\hline
\end{tabular}

We see that the plot of $q_{t}$ versus $\mathrm{t}^{1 / 2}$ is not linear over the whole time range and also does not pass through the origin. This abnormality from the origin can be due to the variance in the rate of mass transfer in the initial and final steps of adsorption. This is the indication of some degree of boundary layer control and further shows that the intraparticle diffusion (or internal diffusion) is not only the rate-controlling step but all may be operating simultaneously. ${ }^{48}$

Graphical representation of the amount of CPH sorbed by MMT versus $\mathrm{t}^{1 / 2}$ reveal two line segments observed (Figure 10). The first part is generally associated with film diffusion, and the following second linear part represents intraparticle diffusion into the porous structure of the sorbent. The y-intercept of the two linear portions is considered a measure of the thickness of the boundary layer; the larger the value of $\mathrm{C}$, the greater is the boundary effect. The boundary layer effect of the initial process of sorption $\mathrm{C}_{1}$ (257.21) was smaller than that effect in the final process of sorption $\mathrm{C}_{2}$ (262.11). Also, the value of the constant $\mathrm{k}_{1}$ (2.08) greater than that of $k_{2}(0.19)$ as represented in Table 7 corresponds to the initial process of sorption on the surface of sorbent particles. This process takes place very fast until reaching the saturation of the solid surface, followed by the sorption of the CPH molecules inside the porous sorbent particles, this step takes place at a much smaller rate compared with first step $\left(\mathrm{k}_{1}>\mathrm{k}_{2}\right){ }^{46}$
Table 7: Parameters of intraparticle diffusion model.

\begin{tabular}{|l|l|l|}
\hline \multicolumn{1}{|c|}{ Model } & \multicolumn{1}{|c|}{ Parameter } & \multicolumn{1}{c|}{ Value } \\
\hline \multirow{3}{*}{$\begin{array}{l}\text { Intraparticle diffusion } \\
\text { model }\end{array}$} & $\mathrm{k}_{1}\left(\mathrm{mg} / \mathrm{g} \mathrm{h}^{1 / 2}\right)$ & 2.08 \\
\cline { 2 - 3 } & $\mathrm{C}_{1}$ & 257.21 \\
\cline { 2 - 3 } & $\mathrm{k}_{2}\left(\mathrm{mg} / \mathrm{g} \mathrm{h}^{1 / 2}\right)$ & 0.19 \\
\cline { 2 - 3 } & $\mathrm{C}_{2}$ & 262.11 \\
\hline
\end{tabular}

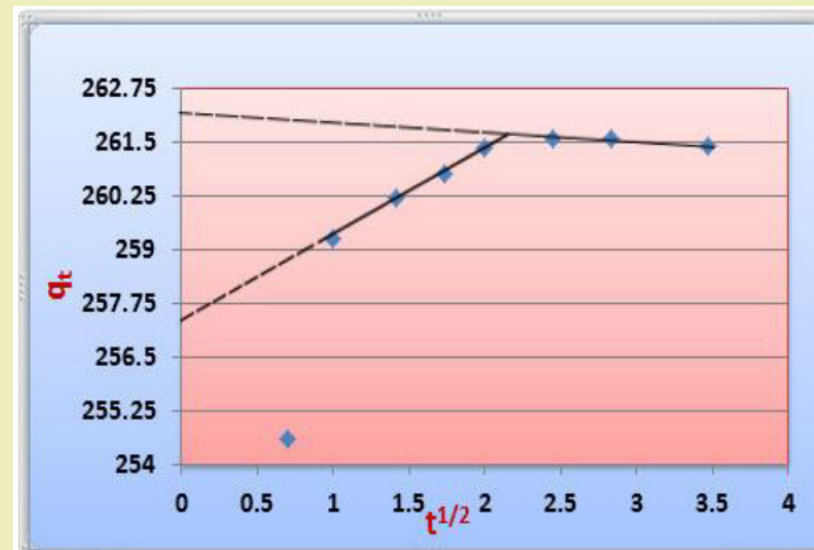

Figure 10: Intraparticle diffusion model of CPH adsorption on MMT.

\section{Adsorption equilibrium isotherms}

\section{Freundlich isotherm}

The Freundlich adsorption isotherm is expressed as

$$
\log q_{e}=\log K_{f}+1 / n \log C_{e}
$$

where $\mathrm{q}_{\mathrm{e}}$ is the amount of drug adsorbed at equilibrium (mg/g), $\mathrm{C}_{\mathrm{e}}$ is the equilibrium $\mathrm{CPH}$ concentration $(\mathrm{mg} / \mathrm{L}), \mathrm{K}_{\mathrm{f}}(\mathrm{mg} / \mathrm{g})$ is considered as relative adsorption capacity (Freundlich constant) and $\mathrm{n}$ is the empirical parameter representing the energetic heterogeneity of the adsorption sites (dimensionless). The linear plot of $\log \mathrm{q}_{\mathrm{e}}$ versus $\log \mathrm{C}_{\mathrm{e}}$ was employed to generate the intercept value of $\log \mathrm{K}_{\mathrm{f}}$ and the slope of $1 / \mathrm{n}$ as indicated in Figure $11 .^{30}$ The magnitude of the exponent, $1 / n$, gives an indication of the favorability of adsorption..$^{49} \mathrm{On}$ an average, favorable adsorption tends to have Freundlich constant $\mathrm{n}$ between 1 and 10 and become more heterogeneous as $1 / \mathrm{n}$ value gets closer to zero. A larger value of $n$ (smaller value of $1 / n$ ) implies a stronger interaction between the adsorbent and the adsorbate and greater the expected heterogeneity, while $1 / \mathrm{n}$ equal 1 indicates linear adsorption leading to identical adsorption energies for all sites. ${ }^{50}$ The correlation coefficient of Freundlich isotherm $\left(\mathrm{R}^{2}\right)$ was 0.9315 . Freundlich isotherm model parameters $\mathrm{K}_{\mathrm{f}}$ and $\mathrm{n}$, calculated according to Equation (10), were $123.51 \mathrm{mg} / \mathrm{g}$ for adsorption capacity and 8.75 for the intensity of the adsorption, the value of $\mathrm{n}$ of this model was 8.75 which falls in the range of $1-10$, indicating favorable adsorption.

\section{Langmuir isotherm}

The Langmuir adsorption model can be written as 


$$
\frac{C_{e}}{q e}=\frac{1}{q_{\max } K_{L}}+\frac{C e}{q_{\max }}
$$

where qe is the amount of drug adsorbed at equilibrium (mg/g), $\mathrm{C}_{\mathrm{e}}$ is the equilibrium CPH concentration in solution (mg/L). $\mathrm{q}_{\max }$ is the maximum adsorption capacity $(\mathrm{mg} / \mathrm{g})$, and $\mathrm{K}_{\mathrm{L}}$ is the Langmuir constant related to the adsorption energy $(\mathrm{L} / \mathrm{mg})$.

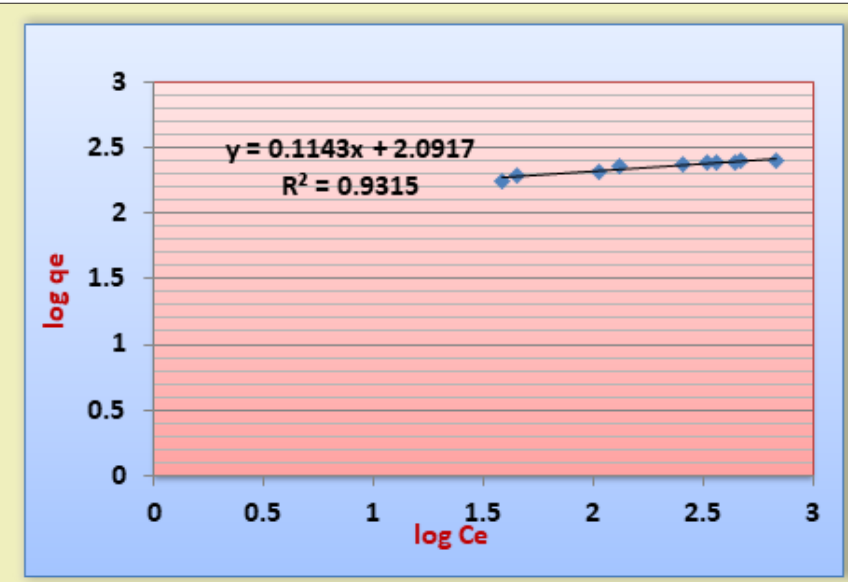

Figure 11: Linear form of Freundlich isotherm for $\mathrm{CPH}$ adsorption on MMT.

The linear plot of $\mathrm{C}_{\mathrm{e}} / \mathrm{q}_{\mathrm{e}}$ versus $\mathrm{C}_{\mathrm{e}}$ was employed to generate the intercept value of $1 / q_{\max } K_{L}$ and the slope of $1 / q_{\max }{ }^{25}$ as indicated in Figure 12. The correlation coefficient of Langmuir isotherm $\left(\mathrm{R}^{2}\right)$ was 0.9992 which shows correlation or linear relationship, Thus, it was found that adsorption of $\mathrm{CPH}$ correlated well with the Langmuir equation. According to Equation (11), the adsorption constants of Langmuir isotherm model parameters, $\mathrm{q}_{\max }$ and $\mathrm{K}_{\mathrm{L}}$, were obtained as $263.15 \mathrm{mg} / \mathrm{g}$ and $0.0460 \mathrm{~L} / \mathrm{mg}$, respectively.

The essential characteristics of the Langmuir equation can be expressed in terms of equilibrium parameter which is a no appreciable constant related to a separation factor or equilibrium parameter. The value of $R_{L}$, calculated on the basis of Eq (12)

$$
R_{L}=\frac{1}{1+K_{L} C_{0}}
$$

where $\mathrm{C}_{\mathrm{o}}$ is the initial concentration of $\mathrm{CPH}(\mathrm{mg} / \mathrm{L})$ and $\mathrm{K}_{\mathrm{L}}$ is the Langmuir constant, ${ }^{51}$ indicates the shape of the isotherm to be either unfavorable $\left(R_{L}>1\right)$, linear $\left(R_{L}=1\right)$, favorable $\left(0<R_{L}<1\right)$ or irreversible $\left(R_{L}=0\right)$. The value of the factor of separation $R_{L}$ indicates the nature of the favorability adsorption process and its feasibility.

\section{Temkin isotherm}

Temkin isotherm represents plotting the quantity sorbed $q_{e}$ against $\ln C_{e}$ and the constants are determined from the slope and intercept. The model is represented by the equations $(13,14)$ bellow

$$
\begin{aligned}
& \mathrm{qe}=\mathrm{B} \ln \mathrm{AT}+\mathrm{B} \ln \mathrm{Ce} \\
B= & \frac{R T}{b_{T}}
\end{aligned}
$$

where $A_{T}=$ Temkin isotherm equilibrium binding constant $(\mathrm{L} / \mathrm{g}) ; \mathrm{b}_{\mathrm{T}}=$ Temkin isotherm constant; $\mathrm{R}=$ universal gas constant (8.314J/mol.K); $\mathrm{T}=$ absolute temperature; and $\mathrm{B}=$ Constant related to the heat of sorption $(\mathrm{J} / \mathrm{mol}) .{ }^{51}$

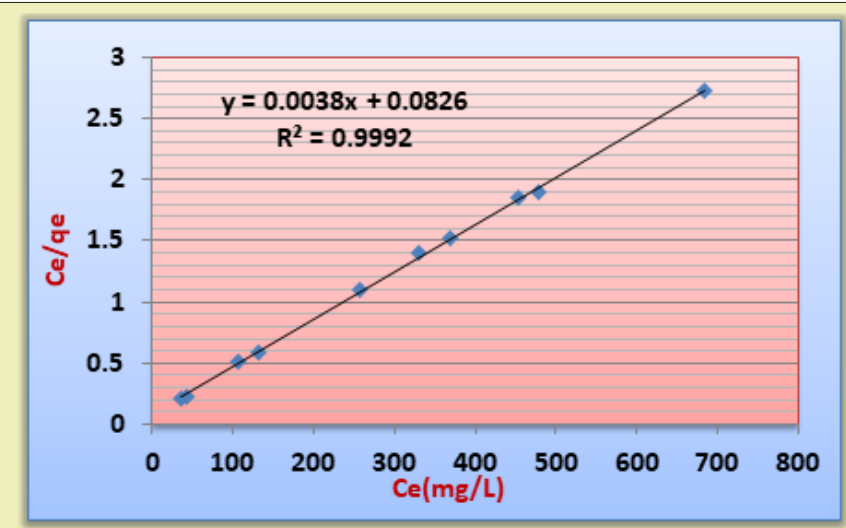

Figure 12: Linear form of Langmuir isotherm for $\mathrm{CPH}$ adsorption on MMT.

The linear plotting of $\ln \mathrm{C}_{\mathrm{e}}$ versus $\mathrm{q}_{\mathrm{e}}$ results in a straight line of slope RT/ $b_{\mathrm{T}}$ and intercept of RT/ $\mathrm{b}_{\mathrm{T}} \ln \mathrm{A}_{\mathrm{T}}$ as shown in Figure $13 .^{52}$ The adsorption constants of Temkin isotherm model parameters, AT, B and bT, were obtained as $42.44 \mathrm{~L} / \mathrm{g}, 25.114 \mathrm{~J} /$ mole and 98.65 $\mathrm{J} /$ mole, respectively. The model indicates the exothermic nature of adsorption as $\mathrm{B}>0$ which is an indicator of heat release during the process. $^{53}$

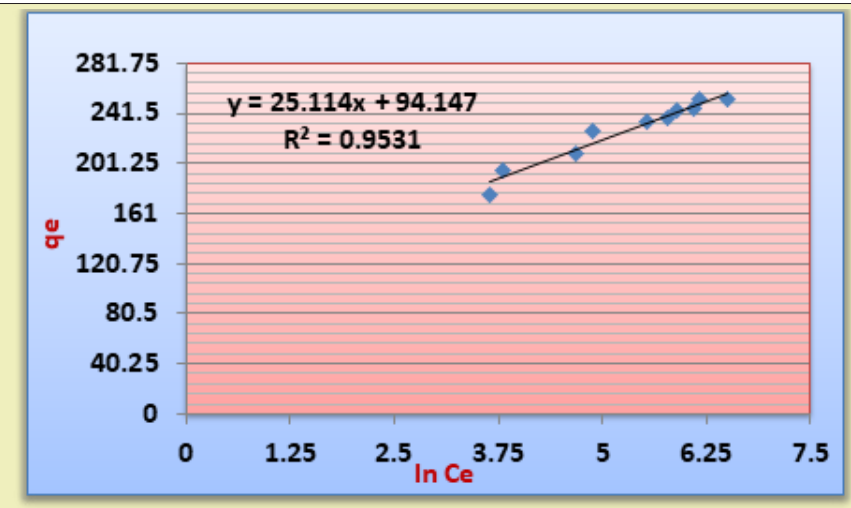

Figure 13: Linear form of Temkin isotherm for CPH adsorption on MMT.

\section{Dubinin Radushkevich isotherm}

$\mathrm{D}-\mathrm{R}$ isotherm is a general model in which assumption is not based on homogenous surface or constant adsorption potential, it gives insight into the biomass porosity as well as the adsorption energy. The model is expressed mathematically by the equation:

$$
\ln q e=\ln q_{\max }-\beta \varepsilon^{2}
$$


(qe is the amount of drug adsorbed at equilibrium (mg/g), $\mathrm{q}_{\max }$ is the maximum adsorption capacity $(\mathrm{mg} / \mathrm{g}$ ), $\beta$ is the activity coefficient $\left(\mathrm{mol}^{2} / \mathrm{J}^{2}\right)$, and $\varepsilon$ is the Polanyi potential). $\varepsilon$ is expressed by the equation ${ }^{48}$

$$
\varepsilon=R T \ln \left(1+\frac{1}{C e}\right)
$$

where $\mathrm{R}, \mathrm{T}$, and $\mathrm{C}_{\mathrm{e}}$ characterize, respectively, the gas constant (8.314 J/mole), absolute temperature and adsorbate equilibrium concentration $(\mathrm{mg} / \mathrm{L})$. Values of qmax and $\beta$ can be determined through the linearization of the D-R isotherm.

Plotting $\ln \mathrm{q}_{\mathrm{e}}$ versus $\varepsilon^{2}$ results in a straight line of slope $\beta$ and intercept $\ln \mathrm{q}_{\max }$ (Figure 14). ${ }^{32}$ The adsorption constants of the model, parameters $\mathrm{q}_{\max }$ and $\beta$, were obtained as $239.87 \mathrm{mg} / \mathrm{g}$ and $8 \times 10^{-5} \mathrm{~mol}^{2} / \mathrm{J}^{2}$, respectively. The parameters calculated from the Freundlich, Langumair, Temkin, and D-R isotherms are presented in Table 8. It is clear from adsorption equilibrium data that fitted in different adsorption isotherm, the coefficient of determination $\left(\mathrm{R}^{2}\right)$ is highest (0.9992) in the case of the Langmuir isotherm compared to other models (Table 8), which suggests that adsorption of $\mathrm{CPH}$ of MMT is best described by Langmuir isotherm. Representing experimental data by the Langmuir isotherm indicates both the homogeneous nature of the MMT surface and the formation of monolayer coverage of $\mathrm{CPH}$ on the surface of MMT. ${ }^{47}$

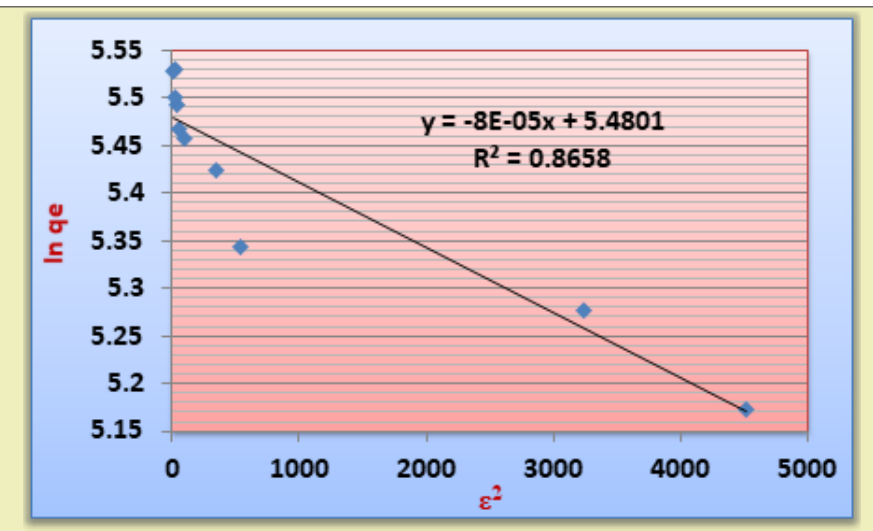

Figure 14: Linear form of D-R isotherm for CPH adsorption on MMT.

The maximum monolayer coverage capacity $\left(\mathrm{q}_{\max }\right)$ from the Langmuir isotherm was determined to be $263.15 \mathrm{mg} / \mathrm{g}$, corresponding to $0.72 \mathrm{mmol} / \mathrm{g}, \mathrm{K}_{\mathrm{L}}$ (Langmuir isotherm constant) is $4.6 \times 10^{-2} \mathrm{~L} / \mathrm{mg}$, $\mathrm{RL}$ (the separation factor) is $7.2 \times 10^{-3}$ indicating that the equilibrium sorption was favorable. With an initial concentration of $1800 \mathrm{mg} / \mathrm{L}$, the equilibrium concentration of $\mathrm{CPH}$ was only $38.48 \pm 0.13 \mathrm{mg} / \mathrm{L}$, suggesting higher than $97 \%$ of $\mathrm{CPH}$ removal from the solution by intercalation into MMT layers.

\section{Error analysis of adsorption isotherms}

Different error functions were employed in order to discover the isotherm model most suitable for representing the experimental data. Equations of $\chi^{2}$ (see equation 6), ARE\% (Eq. 17) and SAE (Eq. 18) were selected to be applied in this study. ${ }^{32}$

$$
\begin{gathered}
A R E \%=\frac{100}{N} \frac{\left[q e_{c a l}-q e_{\text {exp }}\right]}{q e_{e x p}} \\
\mathrm{SAE}=\sum_{\mathrm{i}=1}^{\mathrm{N}}\left(\mathrm{qe} \mathrm{e}_{\exp }-\mathrm{qe} \mathrm{eal}_{\mathrm{cal}}\right)
\end{gathered}
$$

In the above equations, $\mathrm{qe}_{\text {cal }}$ is the theoretical concentration of adsorbate on the adsorbent (which has been calculated from one of the isotherm models) and $\mathrm{qe}_{\text {exp }}$ is the experimentally measured adsorbed solid-phase concentration of the adsorbate adsorbed on the adsorbent. ${ }^{54}$

Table 8: Parameters of Langmuir, Freundlich, Temkin and D-R adsorption isotherms of $\mathrm{CPH}$ on MMT.

\begin{tabular}{|l|l|l|}
\hline \multicolumn{1}{|c|}{ Model } & \multicolumn{1}{|c|}{ Parameter } & \multicolumn{1}{c|}{ Value } \\
\hline \multirow{5}{*}{ Freundlich isotherm } & $\mathrm{R}^{2}$ & 0.9315 \\
\cline { 2 - 3 } & $\mathrm{K}_{\mathrm{f}}(\mathrm{mg} / \mathrm{g})$ & 123.51 \\
\cline { 2 - 3 } & $\mathrm{N}$ & 8.75 \\
\hline \multirow{5}{*}{ Langumair isotherm } & $\mathrm{R}^{2}$ & 0.9992 \\
\cline { 2 - 3 } & $\mathrm{q}_{\max }(\mathrm{mg} / \mathrm{g})$ & 263.15 \\
\cline { 2 - 3 } Temkin isotherm & $\mathrm{K}_{\mathrm{L}}(\mathrm{L} / \mathrm{mg})$ & $4.6 \times 10^{-2}$ \\
\cline { 2 - 3 } & $\mathrm{R}_{\mathrm{L}}$ & $7.2 \times 10^{-3}$ \\
\hline \multirow{5}{*}{ D-R isotherm } & $\mathrm{R}^{2}$ & 0.9531 \\
\cline { 2 - 3 } & $\mathrm{A}(\mathrm{L} / \mathrm{g})$ & 42.44 \\
\cline { 2 - 3 } & $\mathrm{B}(\mathrm{J} / \mathrm{mole})$ & 25.114 \\
\cline { 2 - 3 } & $\mathrm{b}_{\mathrm{T}}(\mathrm{J} / \mathrm{mole})$ & 98.65 \\
\hline & $\mathrm{R}^{2}$ & 0.8658 \\
\cline { 2 - 3 } & $\mathrm{Q}_{\max }(\mathrm{mg} / \mathrm{g})$ & 239.87 \\
\cline { 2 - 3 } & $\beta \mathrm{mol} / \mathrm{J}^{2}$ & $8 \times 10^{-5}$ \\
\hline
\end{tabular}

The values of $\chi^{2}, \mathrm{ARE} \%$ and SAE obtained for the two models (Langmuir and D-R) are listed in Table 9. It is indicated that the Langmuir model yielded the lowest value of and $\chi^{2}$, ARE\% and SAE (0.45, 0.43 and 10.98 , respectively), whereas the D-R model shows higher values $\chi^{2}, \mathrm{ARE} \%$ and SAE $(0.63,0.49$ and 12.29 , respectively). This agrees with the previous values of both $\mathrm{R}^{2}$ and $\mathrm{qe}_{\text {cal }}$ for the Langmuir model to further prove the suitability of the Langmuir model to describe the adsorption process of CPH on MMT.

Table 9: Validity of isotherms parameters.

\begin{tabular}{|l|l|l|}
\hline \multicolumn{1}{|c|}{ Models } & \multicolumn{1}{c|}{ Parameter } & \multicolumn{1}{c|}{ Value } \\
\hline \multirow{3}{*}{ Langmuir model } & $\chi^{2}$ & 0.45 \\
\cline { 2 - 3 } & ARE\% & 0.43 \\
\cline { 2 - 3 } & SAE & 10.98 \\
\hline \multirow{2}{*}{ D-R model } & $\chi^{2}$ & 0.63 \\
\cline { 2 - 3 } & ARE\% & 0.49 \\
\cline { 2 - 3 } & SAE & 12.29 \\
\hline
\end{tabular}




\section{Conclusions}

Ciprofloxacin is proved to successfully intercalate into the interlayers of MMT. The intercalation of a drug in MMT attained to an equilibrium within $4 \mathrm{~h}$ and adsorption process follows pseudo-second order kinetics. The overall rate of the adsorption process is organized by the chemical adsorption route. Further, the optimum $\mathrm{pH}$ was found to be 7.5 for the adsorption route. The adsorption procedure follows the Langmuir model with a maximum amount of CPH intercalated in MMT being $263.15 \mathrm{mg} / \mathrm{g}$. This indicates the homogeneous nature of the MMT. Finally, Yemeni bentonite clay can be applied successfully for environmental and pharmaceutical uses.

\section{Acknowledgments}

None.

\section{Funding}

None.

\section{Conflicts of interest}

The authors declare that they have no conflicts of interest.

\section{References}

1. Genç N, Dogan EC, Yurtsever M. Bentonite for ciprofloxacin removal from aqueous solution. Water Sci Technol. 2013;68:848-855.

2. Zhu H, Njuguna J. Nanolayered Silicates/Clay Minerals: Uses and Effects on Health. In Health and Environmental Safety of Nanomaterials. Woodhead Publishing. 2014: pp. 133-146.

3. Hun Kim M, Choi G, Elzatahry A, et al. Review of clay-drug hybrid materials for biomedical applications: Administration routes. Clays and Clay Minerals. 2016;64(2):115-130.

4. Uddin F. Montmorillonite: An Introduction to Properties and Utilization. Current Topics in the Utilization of Clay in Industrial and Medical Application. In book: Current topics in the utilization of clay in industrial and medical applications. 2018.

5. Nadziakiewicza M, Kehoe S, Micek P. Physico-chemical properties of clay minerals and their use as a health promoting feed additive. Animals. 2019;9(10):714]

6. Antonelli R, Malpass GRP, Da Silva MGC, et al. Adsorption of ciprofloxacin onto thermally modified bentonite clay: Experimental design, characterization, and adsorbent regeneration. J Env Chem Eng. 2020;8(6):104553.]

7. Maged A, Kharbish S, Ismael IS, et al. Characterization of activated bentonite clay mineral and the mechanisms underlying its sorption for ciprofloxacin from aqueous solution. Env Sci Poll Res. 2010; 27(26):32980-32997.

8. Munir M, Nazar MF, Zafar MN, et al. Effective adsorptive removal of methylene blue from water by didodecyldimethylammonium bromide-modified Brown clay. ACS omega. 2020;5(27):16711-16721.

9. Nix DE, Devito JM. Ciprofloxacin and norfloxacin, two fluoroquinolone antimicrobials. Clin Pharm. 1987;6:105-117.

10. Aldred KJ, Kerns JR, Osheroff N. Mechanism of quinolone action and resistance. Biochemistry. 2014;53(10):1565-1574.

11. Kharat R, Jadhav $\mathrm{S}$, Tamboli D, et al. Estimation of ciprofloxacin hydrochloride in bulk and formulation by derivative UV-spectrophotometric methods. Int J Advs Sci Res. 2015;3:137-144.]
12. Ahmed AMK, Hanoon IT, Ahmed SH. Determination of the ciprofloxacin hydrochloride drug in some pharmaceuticals using manufactured membrane selective electrodes. Syst Rev Pharm. 2020;11:622-626.]

13. Martins AF, Vasconcelos TG, Henriques DM. Concentration of ciprofloxacin in Brazilian hospital effluent and preliminary risk assessment: a case study. CLEAN Soil Air Water. 2008;36:264-269.

14. Darr GM, Ludwig U. Determination of the specific surface by adsorption from solution. Matiraux et Constructions. 1973;6(33):232-237.

15. Arjmandi M, Ahmadpour A, Arjmandi A. A new approach for determination of adsorption energy for each adsorption site and improve conventional adsorption isotherms. Int J Petrochem Sci Eng. 2018;3(5):131-142.

16. Cossu R, Ehrig HJ, Muntoni A. Physical-chemical leachate treatment. In: "Solid Waste Landfilling: Concepts, Processes, Technologies" Stegmann R (Ed):2018: pp. 575-632.

17. $\mathrm{Hu} \mathrm{H}, \mathrm{Xu}$ K. Physicochemical technologies for HRPs and risk control. In High-Risk Pollutants in Wastewater. Elsevier. 2020: pp. 169-207.

18. Kaushal A, Singh SK. Adsorption phenomenon and its application in removal of lead from wastewater: a review. Int J Hydrol. 2017:1;38-47.

19. Onsori S, Alipour E. A theoretical investigation on the adsorption of platinol drug on a $\mathrm{ZnO}$ nanocluster: solvent and density functional effect. J Mol Liq. 2018;256:558-564.

20. Bououden W, Benguerba Y, Darwish AS, et al. Surface adsorption of crizotinib on carbon and boron nitride nanotubes as anti-cancer drug carriers: COSMO-RS and DFT molecular insights. J Mol Liq. 2021;338:116666.

21. Li W, Zhao T. Hydroxyurea anticancer drug adsorption on the pristine and doped C70 fullerene as potential carriers for drug delivery. J Mol Liq. 2021;340;117226.

22. Akram M, Saeed AAM. Kabir-ud-Din, Micellar, salt, and organic solvent effects on the rate of [Cu(II)-Gly-l-Ala] ${ }^{+}$complex-ninhydrin reaction. $J$ Mol Liq. 2015;209:367-373.

23. Saeed AAM, Salem TA, Akram M. Influence of ttab/14-s-14 micelles on the rate of the condensation between ninhydrin and mercury-dipeptide complex in absence and presence of salts and organic solvents: a kinetic approach. EJUA-BA. 2020;1(1):1-13.

24. ASTM E11-95 Standard Specification for Wire Cloth and Sieves for Testing Purposes, American Society for Testing and Materials, West Conshohocken, PA. 1995.

25. Allen RF, Standard test methods for determining average grain size (F112). Annual Book of ASTM Standards, Metal-Mechanical Testing; Elevated and Low Temperature Tests; Metallography. 1999.

26. Cazedey ECL, Salgado HRN. Spectrophotometric determination of ciprofloxacin hydrochloride in ophthalmic solution. Advs Ana Chem. 2012;2(6):74-79.

27. Wang CJ, Li Z, Jiang WT, et al. Cation exchange interaction between antibiotic ciprofloxacin and montmorillonite. J Haza Mat. 2010;183(13):309-314.

28. Wu Q, Li Z, Hong $\mathrm{H}$, et al. Adsorption and intercalation of ciprofloxacin on montmorillonite. App Cly Sci. 2010;50(2):204-211.

29. Datta M. In vitro sustained delivery of atenolol, an antihypertensive drug using naturally occurring clay mineral montmorillonite as a carrier. Europ Chem Buln. 2013;2(11):942-951.

30. Fierro V, Torné Fernández V, Montané D, et al. Adsorption of phenol onto activated carbons having different textural and surface properties. Micro Meso Mate. 2008;111(1-3):276-284.

31. Jodeh S, Basalat N, Obaid AA, et al. Adsorption of some organic pheno- 
lic compounds using activated carbon from cypress products. J Chem Pharm Res. 2014;6(2):713-723.

32. Piccin JS, Dotto GL, Pinto LAA. Adsorption isotherms and thermochemical data of FD\&C Red n 40 binding by chitosan. Braz J Chem Eng. 2011;28(2):295-304.

33. Berizi Z, Hashemi SY, Hadi M, et al. The study of non-linear kinetics and adsorption isotherm models for acid red 18 from aqueous solutions by magnetite nanoparticles and magnetite nanoparticles modified by sodium alginate. Wat Sci Tech. 2016;74(5):1235-1242.

34. Bergaya F, Lagaly G. Handbook of Clay Science. Newnes.|Handbook of Clay Science, Amsterdam: Elsevier publication; 2013.

35. Hamilton AR, Hutcheon GA, Roberts M, et al. Formulation and antibacterial profiles of clay-ciprofloxacin composites. Appd Cly Sci. 2014;87:129-135.

36. Panda H, Tiadi N, Mohanty M, et al. Studies on adsorption behavior of an industrial waste for removal of chromium from aqueous solution. South Afr J Chem Eng. 2017;23(1):132-138.

37. Ghogomu JN, Noufame TD, Ketcha MJ, et al. Removal of Pb(II) ions from aqueous solutions by kaolinite and metakaolinite materials. Curr J App Sci Tech. 2013:942-961.

38. Kaur M, Datta M. Diclofenac sodium adsorption on to montmorillonite: adsorption equilibrium studies and drug release kinetics. Adsp Sci Tech. 2014;32(5):365-387.

39. Adamu A, Zewge F. Adsorptive removal of reactive azo dyes using industrial residue (Master thesis). Addis Ababa University. 2008.

40. Desta MB. Batch sorption experiments: Langmuir and Freundlich isotherm studies for the adsorption of textile metal ions onto teff straw (Eragrostis tef) agricultural waste. J Thermo. 2013: pp. 375830.

41. Banerjee S, Chattopadhyaya MC. Adsorption characteristics for the removal of a toxic dye, tartrazine from aqueous solutions by a low-cost agricultural by-product. Arab J Chem. 2017;10:S1629-S1638.

42. Okewale AO, Babayemi KA, Olalekan AP. Adsorption isotherms and kinetics models of starchy adsorbents on uptake of water from ethanolwater systems. Inter J App. 2013;3(1):35-42.

43. Yakout SM. Removal of the hazardous, volatile, and organic compound benzene from aqueous solution using phosphoric acid activated carbon from rice husk. Chem Cent J. 2014;8(1):52.
44. Yakout SM, Elsherif E. Batch kinetics, isotherm and thermodynamic studies of adsorption of strontium from aqueous solutions onto low cost rice-straw based carbons. Carb Sci Tech. 2010;3:144-153.

45. Huang YT, Shih MC. Prediction of adsorption kinetics and isotherms by using linear regression method. Inte J Sci Comm Hums. 2013;1:303320 .

46. Suteu D, Zaharia C, Badeanu M. Kinetic modeling of dye sorption from aqueous solutions onto apple seed powder. Cellu Chem Tech. 2016;50(9-10):1085-1091.

47. Elmorsi TM. Equilibrium isotherms and kinetic studies of removal of methylene blue dye by adsorption onto miswak leaves as a natural adsorbent. J Env Prot. 2011;2(06):817-827.

48. Kumar PS, Senthamarai C, Durgadevi A. Adsorption kinetics, mechanism, isotherm, and thermodynamic analysis of copper ions onto the surface modified agricultural waste. Environmental Prog Sust Eng. 2014;33(1):28-37.

49. Smitha T, Santhi T, Prasad AL, et al. Cucumis sativus used as adsorbent for the removal of dyes from aqueous solution. Arab J Chem. 2012;10:S244-S251.

50. Anah L, Astrini N. Isotherm adsorption studies of Ni (II) ion removal from aqueous solutions by modified carboxymethyl cellulose hydrogel. In IOP Conference Series. Earth and Environmental Science. 2018;160(1):012017.

51. Dada AO, Olalekan AP, Olatunya AM, et al. Langmuir, Freundlich, Temkin, and Dubinin-Radushkevich isotherms studies of equilibrium sorption of $\mathrm{Zn}^{2+}$ onto phosphoric acid modified rice husk. IOSR J App Chem. 2012;3(1):38-45

52. Inyinbor AA, Adekola FA, Olatunji GA. Kinetics, isotherms and thermodynamic modeling of liquid phase adsorption of Rhodamine B dye onto Raphia hookerie fruit epicarp. Water Reso Ind. 2016;15:14-27.

53. Batool F, Akbar J, Iqbal S, et al. Study of isothermal, kinetic, and thermodynamic parameters for adsorption of cadmium: an overview of linear and nonlinear approach and error analysis. Bioinorgc Chem App. 2018: pp. 3463724.

54. Ayawei N, Ebelegi AN, Wankasi D. Modelling and interpretation of adsorption isotherms. J Chem. 2017: pp. 3039817. 